\title{
Design and Implementation of Smart Home Energy Management System Based on GSM Network
}

\author{
Noor H. Saleh \\ Electrical Eng. Department \\ University of Technology \\ Baghdad, Iraq \\ noor.hadi.salih@gmail.com
}

\author{
Bilal A. Mubdir \\ Electrical Eng. Department \\ Sulaimani Polytechnic University \\ Sulaymaniyah, Iraq \\ bilal.mubdir@spu.edu.iq
}

\author{
Asaad M. Al-Hindawi \\ Communication Eng. Department \\ Sulaimani Polytechnic University \\ Sulaymaniyah, Iraq \\ asaad.jasim@spu.edu.iq
}

\author{
Adel H. Ahmed \\ Electrical Eng. Department \\ University of Technology \\ Baghdad, Iraq \\ dradilh152@yahoo.com
}

\begin{abstract}
:
The aim of this research is to design and implement a prototype of a home energy management system based on SMS service on GSM network. The proposed system can remotely monitor and control the home appliances using a mobile phone. The proposed system consists of a microcontroller connecting home appliances and lighting through sensors and relays. The microcontroller is also connected with a GSM module to support this system operate with an existing GSM network. This system is implemented using a GSM module that is connected with the personal computer representing the designed microcontroller. The home appliances, sensors and relays are modeled and simulated using Visual Basic programs. Software programs are developed and built into the personal computer to activate and control the home appliances according to received commands from the user mobile phone or to monitor and send their status to the mobile phone according to user request. The implemented system is tested practically with several cases at different times and it operates successfully with reasonable flexibility and secure operation. A good compatibility of the developed programs is achieved, since the system is running continuously without interruption under normal conditions of GSM network operation. It is found that the execution times for control and monitoring massages are 19.63 seconds and 19.33 seconds respectively.
\end{abstract}

Keywords: Energy management, GSM module, Microcontroller, Sensor, Relay.

\section{INTRODUCTION}

The development of information technologies has led to rapid changes in human lifestyle. The use of electricity is very important as one of the main source of energy that is vital in current modern life. Some kinds of mechanism based on available technology could be used to reduce wastage in electricity usage [1].The smart home concept is the integration of different services within ahome using smart or intelligent system that is mostly based on a common communication system. It assures an economical, secure and comfortable operation of the home and includes a high degree of intelligent function ability and flexibility. The smart home concept virtually includes all technical services within a home. The main advantages of smart home systems are, basically, increased personal comfort and safety, reduced energy cost, simplified installation and flexibility [2]. Energysaving technologies have become more readily available for residential purposes. Such technologies can be classified into two broad categories: energy generation systems and consumption reduction solutions. Technologies for smart appliances are being developed that allow the appliances to shut off or switch to an energy saving state when not in use [3]. Home Energy Management (HEM) describes a class of technologies, including sensors, smart thermostats, and feedback devices seeking to manage residential energy consumption profiles to reduce peak electric demand and consumers' electric bills. A growing number of HEM products and companies have emerged over the past decade, ranging from basic energy displays tow holehome control systems and smart phone apps [4, 5].Conte and Scaradozzi have viewed home automation systems as multiple agent systems (MAS). In this paper, home automation system has been proposed and includes home appliances and devices that are controlled and maintained for home management [6]. Alkar and Buhur have proposed an Internet Based Wireless Home Automation System for Multifunctional Devices. This paper proposes a low cost and flexible web-based solution, but this system has some limitations such as the range and power failure [7]. Jawarkar Ahmed, Ladhake, and Thakare have proposed remote monitoring through mobile phone involving the use of spoken commands. The spoken commands are generated and sent in the form of text SMS to the control system and then the microcontroller on the basis of SMS takes a decision of a particular task [8]. Manouchehr Ghahramanian Golzar and Hamid Reza Tajozzakerin have discussed a design and implementation of an internet-based smart remote control system for home automation, dedicated to power management that adapts power consumption of available power resources according to user comfort and cost criteria [9]. Mansour H. Assaf, et al have presented the design and implementation details of home control and security system based on field programmable gate array (FPGA) By using their system, the user can interact directly with the system through a web-based interface over the Internet, while home appliances like air conditioners, lights, door locks and gates are remotely controlled through a user-friendly web page. An additional feature that enhances the security aspect of the system was its capability of monitoring entry points such 
as doors and windows so that in the event any breach, an alerting email message is sent to the home owner instantly [10]. Hyung-Chul Jo, et al had discussed scheduling method for HEMS the smart heating and air conditioning that considers customer convenience as well as characteristics of thermal appliances in a smart home environment. The prototype software based on the proposed method for HEMS is also implemented [11].

F. Baig, et al, in this paper, the proposed method was encouraging and cost effective. It has given an incentive to consume. The consumer can easily control its appliances remotely with the click of a button using the microcontroller interface with the Zigbee transceiver is on standard RS232 interface. A graphical user interface is provided to the user where the data of its consumption are stored in a file [12]. Bilal Mubdir, et al has proposed a design of smart home energy management system SHEMS for saving energy [13]. The paper has aimed at reducing the consumption energy by detecting the residents' activity and identifying it among three states: Active, Away, or Sleep. The SHEMS is designed with an algorithm that is based on Hidden Markov Model (HMM) in order to estimate the probability of the home being in each of the above states [13].

The objectives of this research are: (a) Design a home system consists of a microcontroller connecting with home appliances and lighting through sensors and relays. The microcontroller is also connected with a GSM module to support this system operate with an existing GSM network. (b) Implement the proposed system by using a GSM module connecting with the personal computer representing the designed microcontroller. The home appliances, sensors and relays are modeled and simulated using Visual Basic software. (c) Develop programs to control the home appliances and monitor their status.

\section{DESCRIPTION OF PROPOSED SYSTEM}

The proposed system is illustrated in figure 1.The mobile phone and GSM module represent the physical components of the system while the microcontroller unit MCU, relays, motion sensors and home appliances are modeled and simulated using the personal computer PC, based Visual Basic (VB.6).

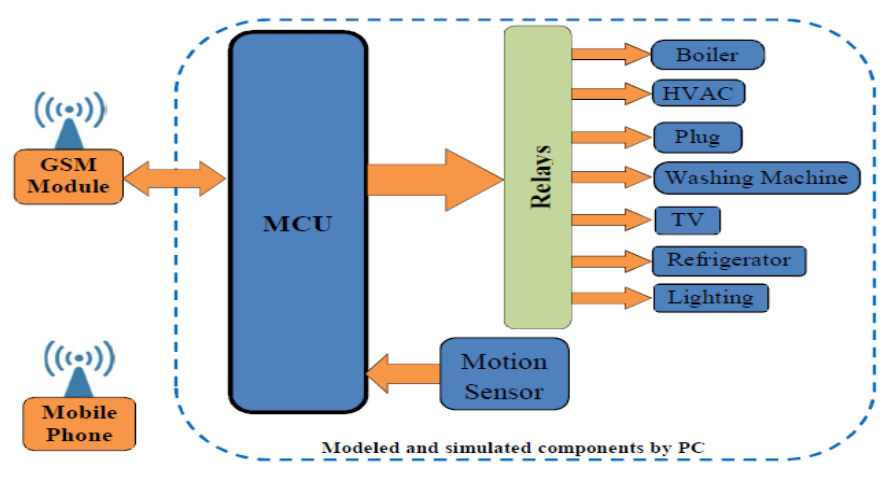

Figure1: Block diagram of the designed system.
The microcontroller unit controls the home appliances according to the received commands from the user mobile phone (by using SMS service on the GSM network) or monitors and sends their status to mobile phone according to user request. The software programs are developed to operate the proposed system remotely (by using the SMS) with the capability if switching ON or OFF the home appliances instantaneously, monitoring the current status of the individual appliance

\subsection{Mobile Phone}

Mobile phones that can be used in the proposed system are normally of second generation $2 \mathrm{G}$ or third generation $3 \mathrm{G}$ phones, because these phones use more powerful digital communication techniques, which have allowed them to provide a wider range of services than before and they send and receive their signals in a very different way from their predecessors. This allows them to support much higher data rates than before, and hence to provide more demanding services such as video calls and high speed Internet access [14].

\subsection{GSM Module}

The used type of GSM module is SM5100B-D GSM/GPRS Module and is pictured and shown in figure.2a.figure. $2 \mathrm{~b}$ shows the functional block diagram of SM5100B-D that is made through a 60 pins board-toboard connector, which provides all hardware interfaces between the module and customers' boards except the $\mathrm{RF}$ (Radio Frequency) antenna interface [15]. Based on an advanced design scheme SM5100B-D integrates the RF and baseband onto one small PCB. It can fulfill all the functions of RF signal receiving and transmitting, baseband signal processing and audio signal processing so that we can develop all kinds of our own wireless terminal products with very few extra components. The main hardware interfaces of SM5100B-D consist of power supply interfaces, serial interfaces, audio interfaces, SPI serial LCD interface, 4X6 matrix keypad interface, standard SIM interface, RF antenna interface, etc. It is integrated with the TCP/IP protocol and supports an extended AT commands which are very suited for developing all kinds of the customized applications [15].

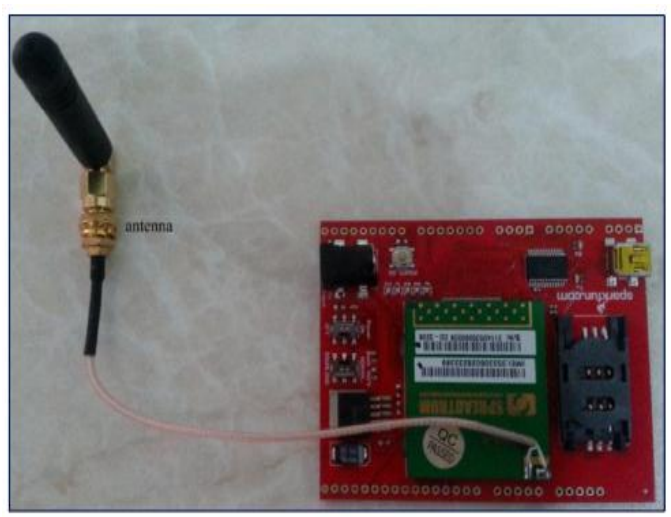

(a) 
Figure 2: SM5100B-D GSM/GPRS Module: (a) Module picture and (b) Functional block diagram of SM5100B -D.

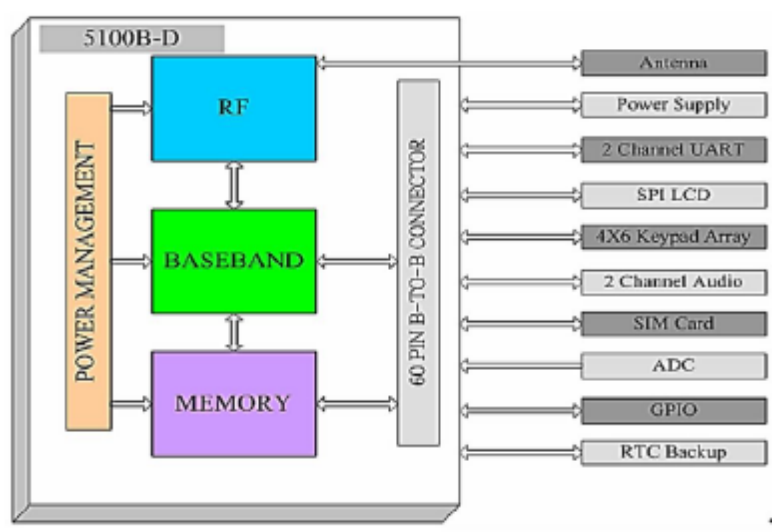

Figure 2 (b) continued

\subsubsection{UART Interface}

SM5100B-D provides two UART (Universal Asynchronous Receiver \& Transmitter) interface: UART0 and UART1whose circuit diagrams are illustrated in figure 3. The UART0 supports full function UART and supports baud rate up to 460800 bps. It is generally used as AT command or download. By default, UART0 support 3-wire standard, CTS0, RTS0, DCD0, RI0 is invalid. [15].

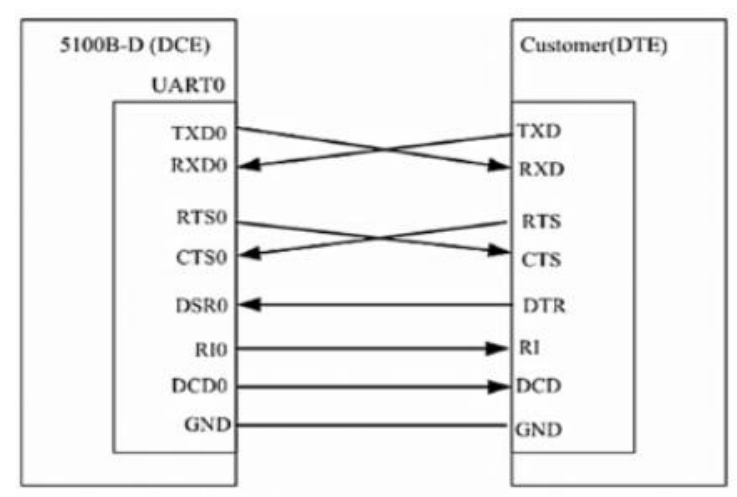

(a)

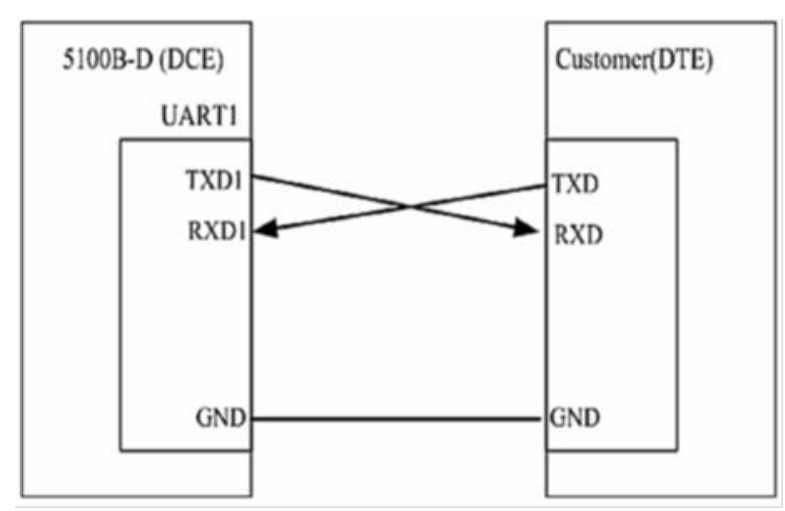

(b)
Figure 3: (a) UART0 and (b): UART1 interface of the SM5100B-D Module.

\subsubsection{Antenna Interface}

SM5100B-D has an RF interface impedance of $50 \Omega$. The user can plug the antenna to the RF pad or GND pad [15].

\subsubsection{SIM Card Interface}

SM5100B-D supports both $1.8 \mathrm{~V}$ and 3.0V SIM cards (5.0V not supported).

\subsubsection{FT232R IC}

FT232R IC is a USB to UART communication IC which is an important communication bridge between the SM5100B-D GSM/GPRS module device and PC (haven't a physical serial port) through an existing USB. The FT232R IC circuit diagram as a USB to UART interface is shown in figure 4 [16].

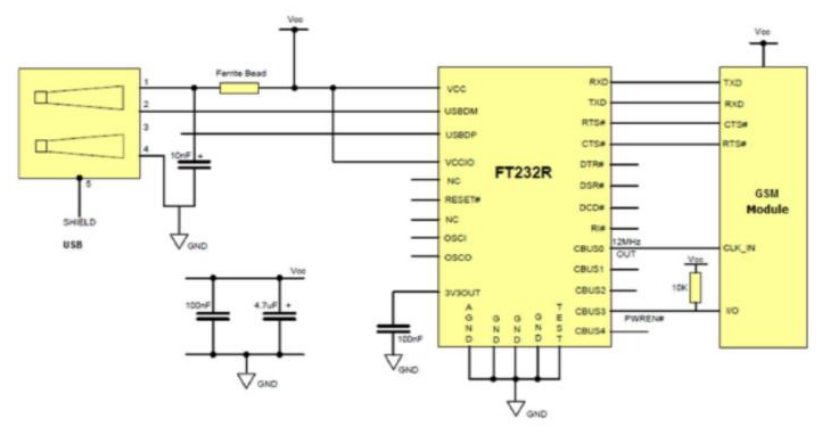

Figure 4: Pin configuration of the USB to UART Interface through FT232R IC [16].

\section{MODELING AND SIMULATION OF SYSTEM COMPONENTS}

The MCU, motion sensors, relays and home appliances are modeled and simulated using Visual Basic.6 (VB6) program. The system modeling and simulation have been applied to a prototype of a proposed home drawing shown in figure 5.

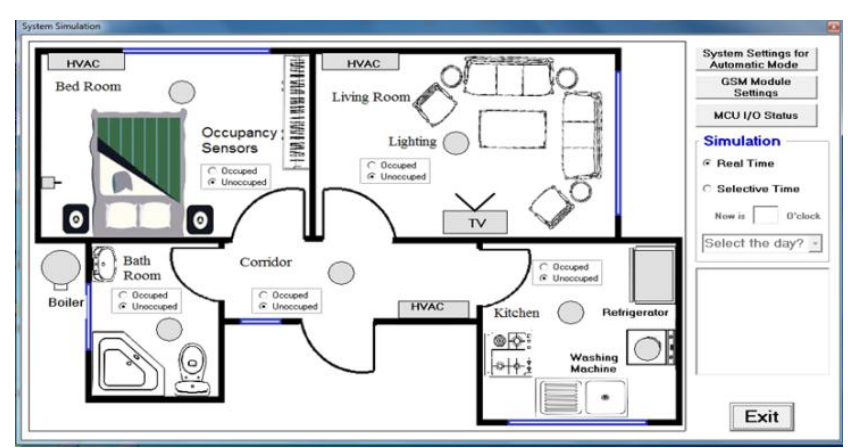

Figure 5: The modeled motion sensors and appliances in the proposed home prototype. 
The above prototype consists of living room, bedroom, kitchen and bathroom as well as a corridor. By using VB6, the motion sensors and the appliances have been modeled using the tools provided in the VB6, such as Shapes, Option Buttons, etc. The prototype, including the modeled motion sensors and appliances. When the system simulation software program is running, the following options related to the system are displayed:

1. System Setting for Automatic Mode

2. GSM Module Setting

3. MCU I/O status.

The above options are displayed as shown in figure 5 when the system simulation main program which is called "System Simulation", is executed. The "System Simulation" is the main interface of the software that establishes the whole software system. The software system architecture is illustrated in figure 6. The three options which are available in the main interface are linked to separated interfaces of other sub-programs and could be activated only by clicking over their buttons as shown in figure 5.

\subsection{Simulation of $\mathrm{MCU}$}

The microcontroller unit described in figure 1 is modeled and simulated to display the input/output status for the pins proposed MCU as shown in figure 7.

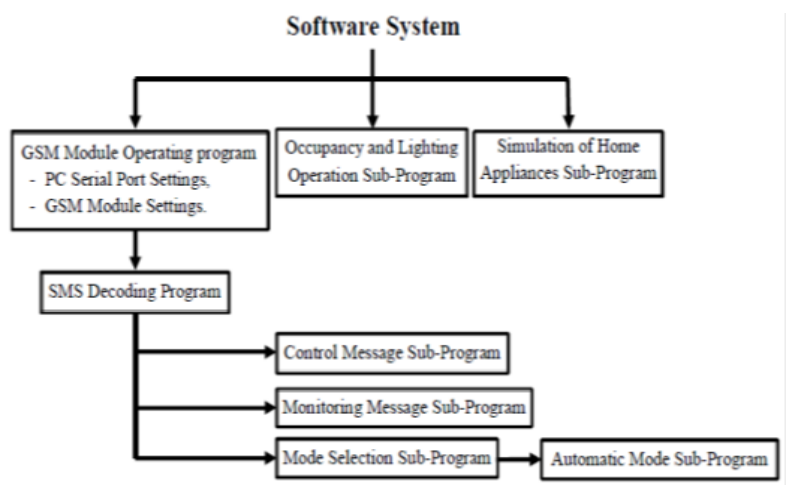

Figure 6: Architecture of main system program.

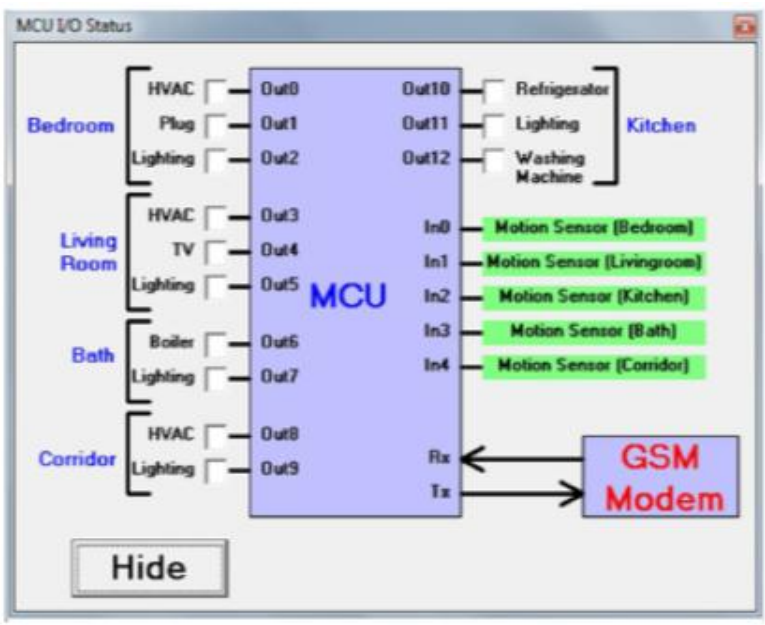

Figure 7: Modeled and simulated MCU pin status

\subsection{Representations of Home Appliances}

The proposed home appliances are represented by the symbols and shapes given in Table 1. In the programming, the home appliances are represented by flags, as described in Table 2. These flags may have a logical value $(0$, or 1$)$ and they are responsible to operate the appliances $(\mathrm{ON}$, or $\mathrm{OFF})$ by changing the $\mathrm{I} / \mathrm{O}$ pins of the MCU and consequently through the connected relays. The flow chart of the simulation sub-program for home appliance operation is shown in figure 8 .

Table 1: Home appliances and their representations.

\begin{tabular}{|c|c|c|c|}
\hline Appliance & Symbol & ON State & OFF State \\
\hline Lighting & & & \\
\hline HVAC & & & \\
\hline TV (television) & TV & & $\square$ \\
\hline Boiler & & & \\
\hline Washing Machine & & & \\
\hline Plug & $\square$ & & \\
\hline Refrigerator & & & \\
\hline
\end{tabular}

Table 2: Flags of home appliances.

\begin{tabular}{|c|c|c|}
\hline Location & Appliances & Flag Name \\
\hline \multirow{4}{*}{ Bedroom } & HVAC & f_hvac_bed \\
\cline { 2 - 3 } & Plug & f_plug_bed \\
\cline { 2 - 3 } & Lighting & f_L_bed \\
\hline \multirow{2}{*}{$\begin{array}{c}\text { Riving } \\
\text { Room }\end{array}$} & HVAC & f_hvac_live \\
\cline { 2 - 3 } & TV & f_tv_live \\
\cline { 2 - 3 } Kitchen & Lighting & F_L_live \\
\cline { 2 - 3 } & Refrigerator & f_refrig_kit \\
\cline { 2 - 3 } & Washing machine & f_wm_k_kit \\
\hline \multirow{2}{*}{ Bath } & Lighting & f_L_bath \\
\cline { 2 - 3 } & Boiler & f_boiler_bath \\
\hline \multirow{2}{*}{ Corridor } & HVAC & f_hvac_cor \\
\cline { 2 - 3 } & Lighting & f_L_cor \\
\hline
\end{tabular}

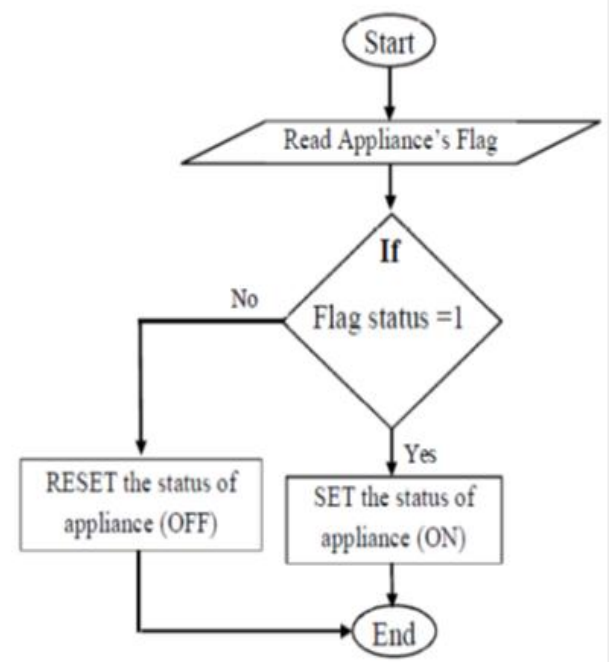

Figure 8: Flow chart of simulation of home appliances operation sub-program. 


\subsection{Occupancy and Lighting Operation}

The principle of motion sensor's operation is to generate a signal representing the occupancy or the presence of a person in a specified place or room, and send it always to the MCU for the rest necessary processing. According to this signal, the MCU excites the relay always to switch $\mathrm{ON}$ or OFF the lighting. The lighting is set $\mathrm{ON}$ for a certain time (Occupancy Time Setting) that is predefined. In the designed software, the occupancy time setting could be selected in the range of minutes, according to the customer convenience versus energy consumption. This time works as a duration value for a programmable delay (Occupancy Delay), this delay is activated only at that instant of place occupancy changed from the unoccupied state into occupied state and the lighting is turned ON. When the occupancy delay duration ends, the occupancy and lighting operation sub-program checks the motion sensor signal, and so the room or place occupancy. Two cases could be expected here: Case (1): If the room or place still occupied, then the lighting stays $\mathrm{ON}$ and the occupancy delay will re-activate and repeated. Case (2): If the room or place is not occupied by any person, the lighting will be turned OFF and occupancy delay will be deactivated. In all of our operations, the selected occupancy time setting was five (5) minutes. The sensor operation is simulated according to the flow chart described in Fig. 9. This sub-program is called "Occupancy and Lighting operation".

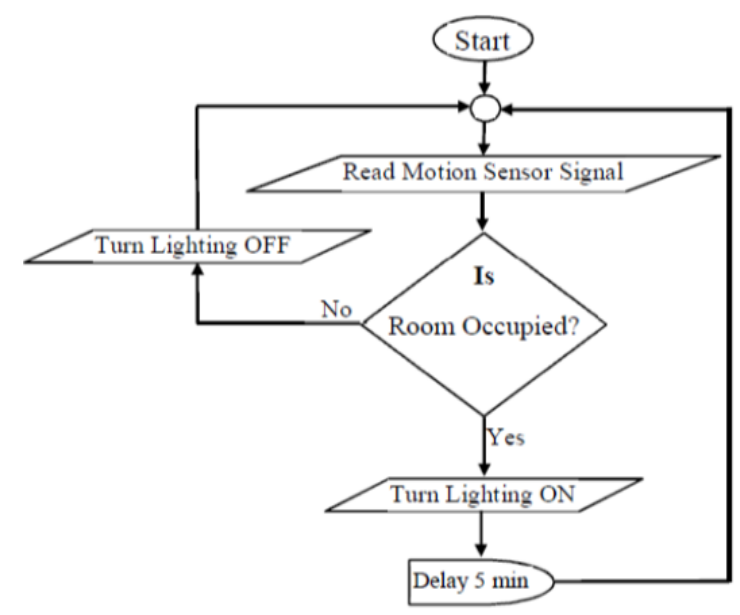

Figure 9: Flow chart of sensor operation simulation.

\subsection{GSM Module Settings}

In this part of the software, the connection settings of the GSM module with proposed system can be controlled. Generally, it consists of two subprograms, the first sub-program is to set the computer's serial port and test its operation, where the second sub-program is to set the GSM module and test its operation. The GSM module can be set by using its AT commands. Each operation and parameter in the GSM module can be Controlled by using the AT commands. Also, in this part of the software the mobile phone number should be defined as an input as shown in figure 10 .

\subsubsection{PC Serial Port Settings}

In $\mathrm{PC}$, many ports are used for $\mathrm{I} / \mathrm{O}$ purposes. As shown in Fig.10, the port number should be specified, as well as, the port baud rate. The system has been operated by using a baud rate of 9600 bps which is compatible with that of the GSM module. This first sub-program is executed by click on the "Connect" button as shown previously in figure 10. The flow chart of the first subprogram developed to works as shown in figure 11.

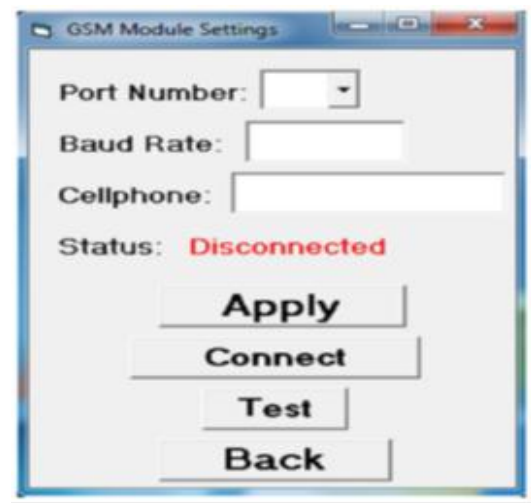

Figure.10: GSM module setting interface.

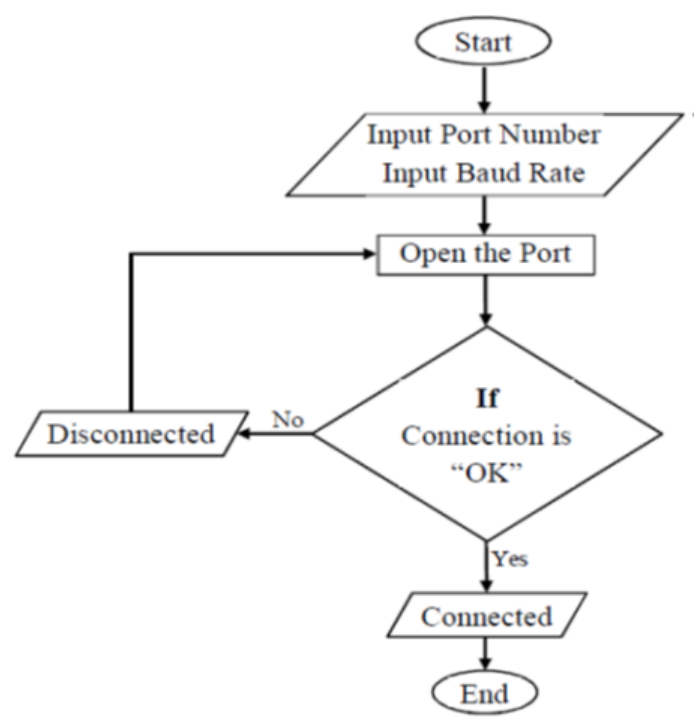

Figure11: Flow chart of computer serial port setting and test

\subsubsection{GSM Module Settings and Test}

The setting and the test of the GSM module can be achieved by clicking on the "Test" button in as shown previously in Fig.10. Here, the second subprogram is executed to perform the followings:

a) Set SMS format

b) Change the method of the new incoming message's indication.

The SMS format consists of two modes, PDU and Text mode (more details in Appendix A). Whereas, the incoming message may be received in different ways, such as saving it in the GSM module's internal memory, 
SIM card, or receive it directly by the Data Terminal Equipment (DTE), which is here the PC. In this subprogram, by using the AT commands, the SMS format will set to the Text Mode and the method of new incoming message's indication will set to the direct indication method. Then, the GSM module will be tested after the performing the setting. Each setting change should be followed by a reply from the GSM module, the reply either "OK" or "Error". So the GSM module will be tested by testing the reply each time after changing the settings. If the reply is "OK", a pop-up dialog box will be appeared indicating that the "GSM Module is Ready" as shown in figure 12. The flow chart of the GSM module settings' subprogram is shown in figure 13 .

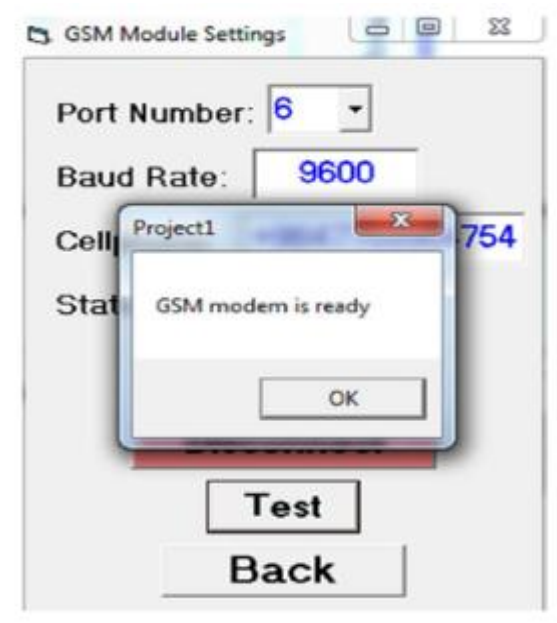

Figure 12: Indication of readiness of GSM module.

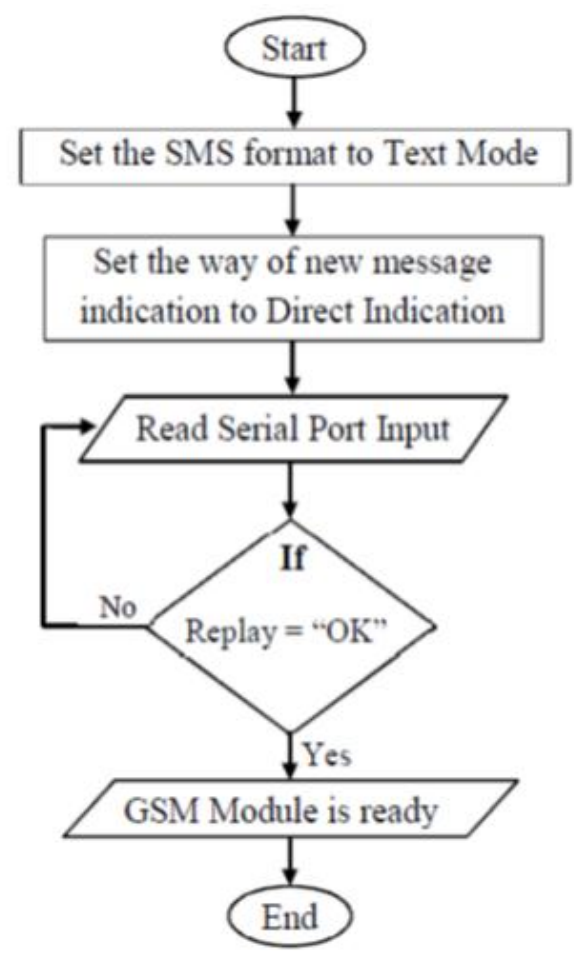

Figure 13: GSM module settings' sub-program

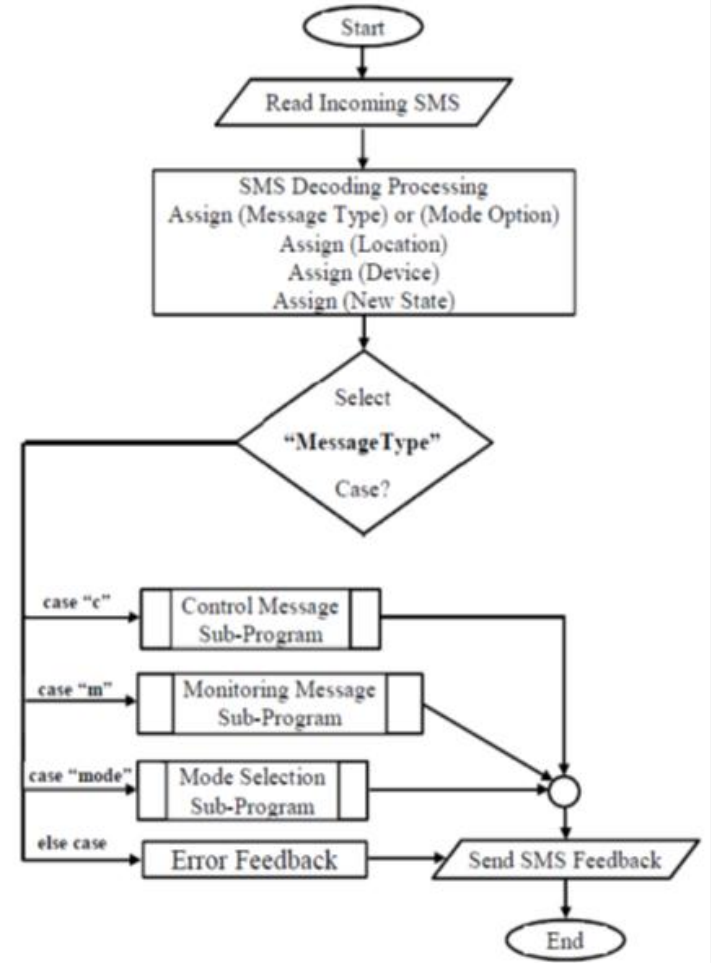

Figure 14: Flow chart of decoding the incoming SMS Based on its format.

\subsection{SMS Decoding and Executing Program}

The incoming SMS decoded using a decoding program that decodes the incoming message from the GSM module according to its format as illustrated in the flow chart in figure 14. According to the flow chart of figure 14 , there are three formats of text messages could be used. One is sent for controlling the home appliances and the other for the monitoring the status of the appliances while the third message for selecting the mode of system operation, manual or automatic. If there is any mistake in the format of the sent message, this can be considered as an error message.

\subsubsection{Control Message}

It consists of four parts as shown in Table 3. The first part is the "Message Type", it means control message represented by a letter " $C$ ". The second one is the "Location", while the third and the fourth parts represent the "Appliance" and its "new status" respectively. Taking into consideration, there is a single space between each part and the next one, and the letters are not case sensitive for the example, if ones want to change the status of the HVAC in the living room: the text message is written as follows:

\section{C living room hvac on}


Table 3: The parts of control message format.

\begin{tabular}{|c|c|c|c|}
\hline Message Type & Location & Appliance & New Status \\
\hline \multirow{4}{*}{} & Corridor & HVAC & \\
& Living room & Lighting & \\
& Bathroom & TV & ON \\
C & Kitchen & Bashing machine & OFF \\
& Bedroom & Boiler & \\
& & Plug & \\
& & Refrigerator & \\
\hline
\end{tabular}

Controlling any appliance remotely can be achieved by using the same format of the above message. After the incoming SMS is decoded as previously shown in figure 14 , the control message sub-program is running, as well as, Location, Appliance, and New status are assigned and ready for further processing. This sub-program changes the current status of the assigned appliance to the assigned new status at the assigned location. Then, a feedback returns and confirms the control operation. The control message subprogram illustrated in the flow chart in figure 15 .

\subsubsection{Monitoring Message}

The format of this message consists of three parts as shown in Table 4. The first part is the "message type", it means monitoring message represented by a letter " $M$ ". The second one is the "Location", while the third one represents the "Appliance". Taking into consideration; there is a single space between each part and the next one, and the letters are not case sensitive For the example, if ones wants to know the status of the boiler in the bathroom whether it is OFF or ON, the text message is written as follows:

\section{M bathroom boiler}

Table 4: The parts of monitoring message format.

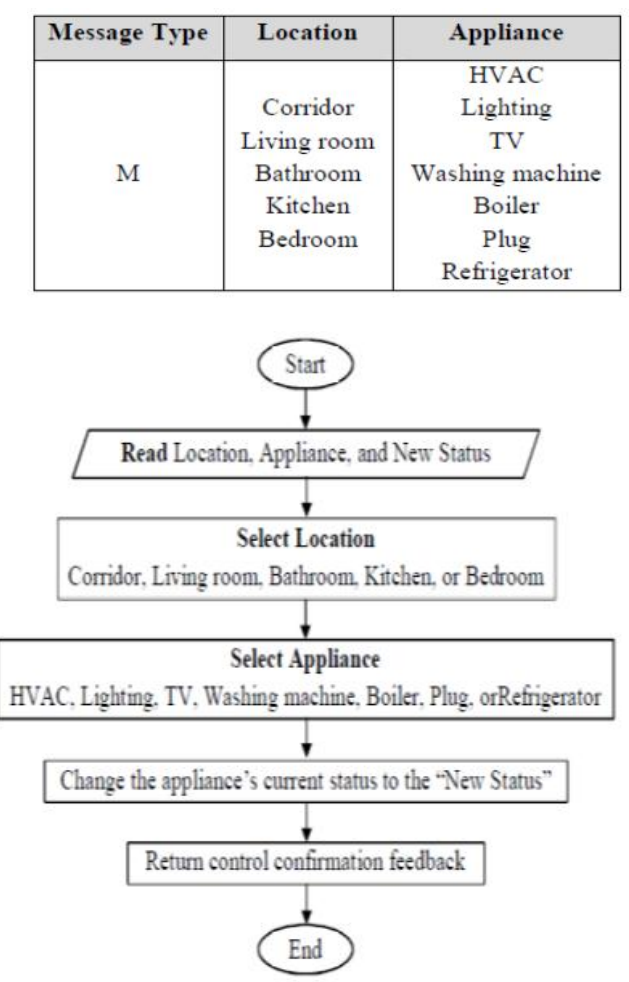

Figure 15: Flow chart of control message sub- program.

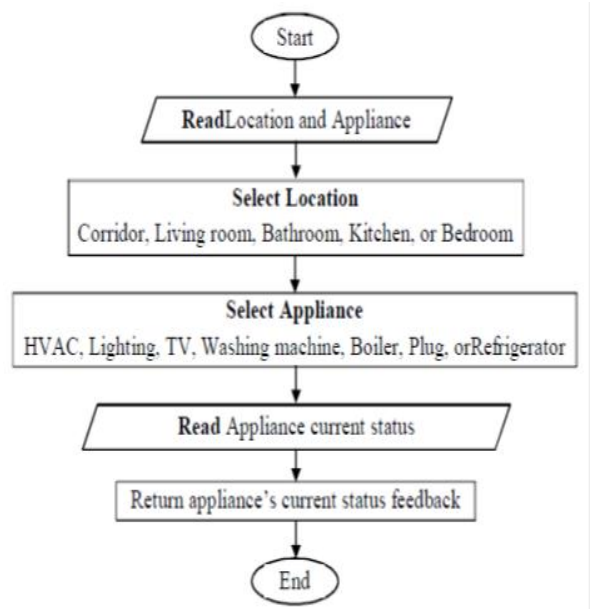

Figure 16: flow chart of monitoring message sub-program.

Monitoring any appliance remotely can be achieved by using the same format of the above message. After the incoming SMS decoded, as previously shown in Fig.4, the monitoring message sub-program is running, as well as, Location and Appliance are assigned and ready for further processing. This sub-program reads the current status of the assigned appliance (read the appliance flag) at the assigned location. Then, a feedback returns and includes the current status of the appliance. The monitoring message sub-program is illustrated in the flow chart in figure 16.

Finally, the proposed system included all of its divisions; the personal computer, GSM module and the mobile phone are operated and ready for test as shown in figure 17 .

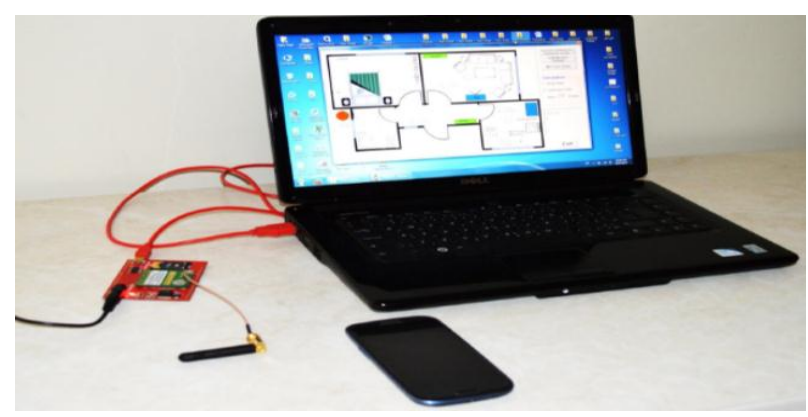

Figure 17: The final proposed system included GSM module and mobile phone.

\section{SYSTEM TESTS AND RESULTS}

Different tests can be performed to examine and evaluate the proposed system. Three system tests are performed for controlling and monitoring purposes, as well as the test in case of error state. The execution time is also measured for the proposed system. 


\subsection{Test 1}

In this test, the status of HVAC in the living room is changed from OFF to ON status. To change the HVAC's status, the message should be written and sent as follows:

\section{C livingroom hvac on}

As shown in figure 18, the expected received message as a reply to the control action stating as follows:

\section{"Dear user}

The HVAC in the LIVINGROOM now is ON". At the same time the status of HVAC changes to the ON status (the color of the HVAC symbol becomes green) as shown in figure 19.

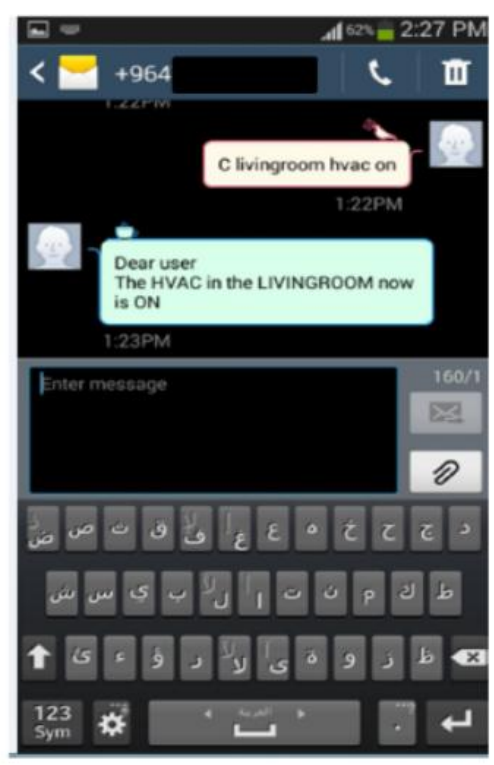

Figure 18: The sent and received SMS of test 1.

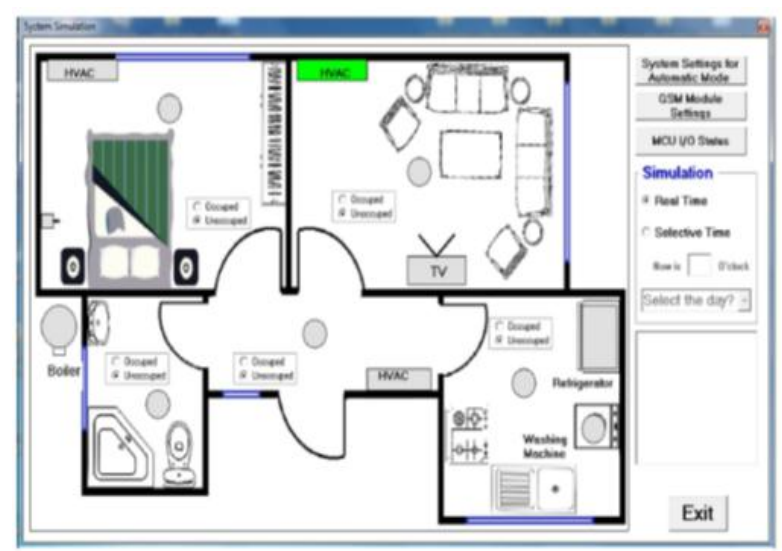

Figure 19: The ON status for the HVAC in the living room.

\subsection{Test 2}

In this test, the status of the boiler in the bathroom is changed from OFF to ON status. Figure 19 shows the status of the boiler in the bathroom (OFF). To change the boiler's status, the message should be written and sent as follows:

\section{c bathroom boiler on}

As shown in figure 20, the expected received message as a reply to the control action states as follows:

\section{"Dear user}

The BOILER in the BATHROOM now is ON"

At the same time the status of the boiler changes to the ON status (the color of boiler symbol becomes red) as shown in figure 21 .

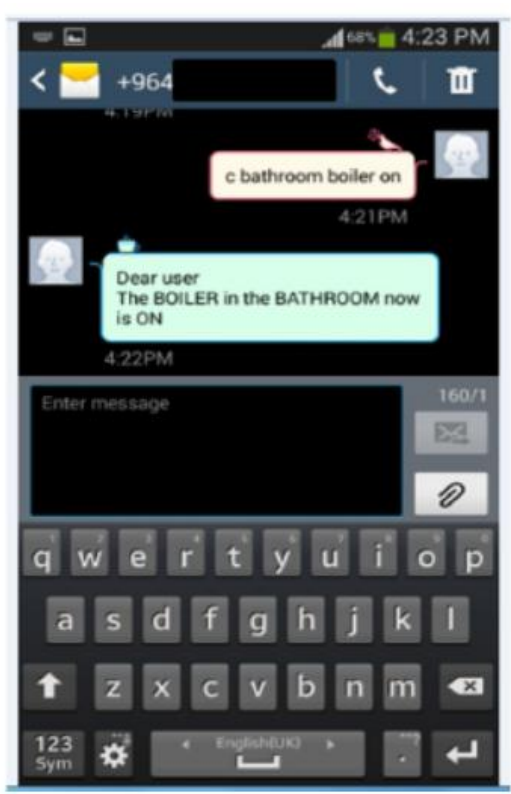

Figure 20: The sent and received SMS of test 2.

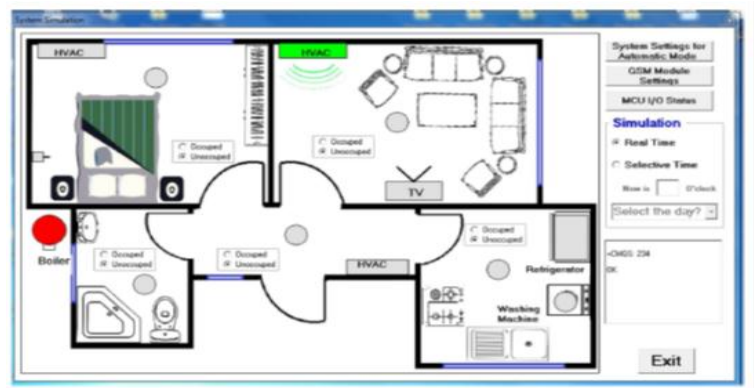

Figure 21: Shows the Status ON for the boiler in the bathroom.

\subsection{Test 3}

In this test, the status of HVAC in the corridor is changed from OFF to ON status. Fig. 21 shows the status of HVAC in the corridor (OFF). To change the HVAC's status, the message should be written and sent as follows:

\section{c corridor hvac on}

As shown in figure 22, the expected received message as a reply of control action stating as follows:

\section{"Dear user}

\section{The HVAC in the CORRIDOR now is ON"}

At the same time, the status of HVAC changed to the ON status (the color of HVAC symbol becomes green) as shown in figure 23 . 


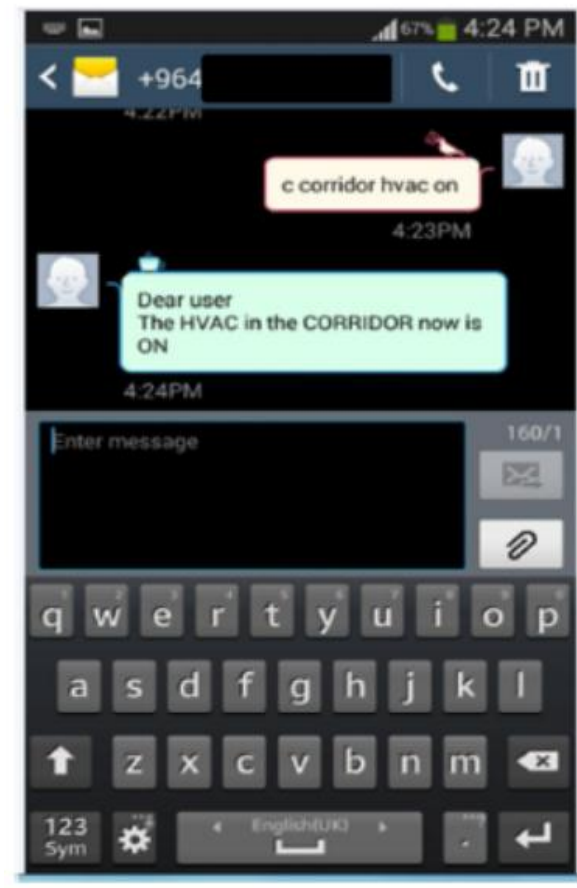

Figure 22: The sent and received SMS of test 3.

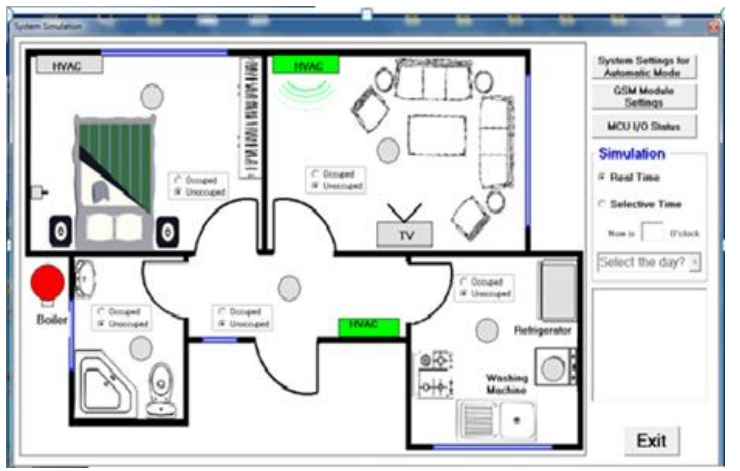

Figure 23: The Status ON for the HVAC in the corridor.

\subsection{Error Message Format Test}

This test is achieved when there is an error in the format of the sending message. For example, if the following mistake message is written as:

\section{G living room hvac}

It is wrong, because there is no letter $\mathrm{g}$ in the format of monitoring or controlling statement, even in changing the system mode. Therefore a message is received as follows and shown in figure 24 .

\section{"Dear user}

The request format that you sent is not accepted by the system"

The set of the above tests is repeated for many times and the same results are obtained and confirm that the proposed system operates successfully. It is seemed that a good compatibility of the developed programs is achieved.

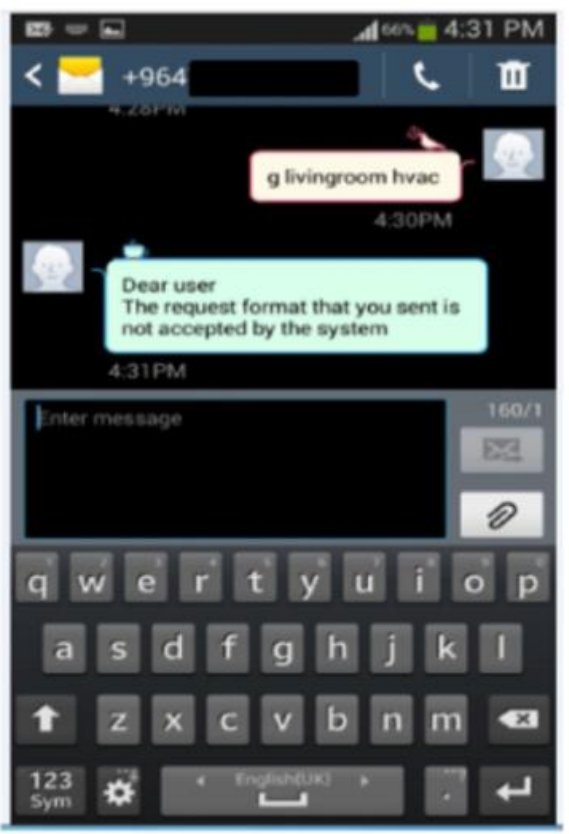

Figure 24: The sent and received SMS of the error format test.

\subsection{Measurements of Execution Time}

During the above tests, the execution time of the proposed system starts when the SMS is sent by the user mobile phone until the message is received under normal conditions of the existing network (not busy), this time has been measured. All the measurements are given in the Table 5 for command messages and Table 6 for monitoring messages, where: Tmg: The measured time from sending the control command (by mobile phone) to receiving this command (by GSM module at home system). Tre : The measured time from receiving the control command (by home system) to executing this command by the MCU. Tem: The measured time of executing the control command (by the MCU) to receiving the SMS of the current appliance status (by mobile phone). Tmsm: The measured time from sending the monitoring command (by mobile phone) to receiving the message of current appliance status (by mobile phone). From the above tables the execution time for controlling (average of 19.63Sec.) greater than the execution time for monitoring (average of $19.33 \mathrm{Sec}$.). This means that $0.3 \mathrm{Sec}$ or $330 \mathrm{~ms}$ are the differences between the times. This time difference is equivalent to the time spent to change the appliance status. The measured times are recorded and depended on the processing time of the microcontroller.

Table 5: Measured execution time for control's command messages.

\begin{tabular}{|c|c|c|c|c|}
\hline Message Type & $T_{m g}$ (Sec.) & $T_{r e}$ (Sec.) & $T_{e m}$ (Sec.) & $\begin{array}{c}\text { Total time } \\
\text { (Sec.) }\end{array}$ \\
\hline C livingroom hvac off & 9.32 & 1.00 & 9.33 & 19.65 \\
\hline C bathroom boiler on & 9.30 & 1.05 & 9.31 & 19.66 \\
\hline C corridor hvac on & 9.31 & 0.96 & 9.32 & 19.59 \\
\hline
\end{tabular}


Table 6: Measured execution time for control's command messages.

\begin{tabular}{|c|c|}
\hline Message Type & $\boldsymbol{T}_{\boldsymbol{m s m}}(\mathbf{S})$ \\
\hline M corridor hvac & 19.50 \\
\hline M livingroom hvac & 19.20 \\
\hline M kitchen refrigerator & 19.30 \\
\hline
\end{tabular}

\section{CONCLUSION}

In the present research, a proposed system of energy management for the home appliances has been designed, and implemented using SMS services of the GSM network. By this system the home appliances have remotely been controlled using mobile phones and the statuses of these appliances have been monitored. Developed programs with a simple algorithm have been implemented. The proposed system has been tested and it has seemed to work successfully. Since the system has a simple algorithm, it can be developed according to the user requirements. It is found that the execution time for the control function is 19.63 seconds and 19.33 seconds for the monitoring function. A good compatibility of the developed programs is achieved because the system is running continuously without interruption. The proposed system is considered to be a good security system for the home owner.

\section{REFERENCES}

[1] M. Abd Wahab, N. Abdullah, A. Johari and H. Abdul Kadir, "GSM Based Electrical Control System for Smart Home Application," Journal of Convergence Information Technology, pp. 33-39, Vol.5, No.1, 2010.

[2] R. Lutolf, "Smart Home concept and the integration of energy meters into a home based system," In Proceedings of the Seventh International Conference on Metering Apparatus and Tariffs for Electricity Supply, pp. 277-278, Glasgow, 1992,

[3] J. W. Chuah, A. Raghunathan and N. K. Jha, "An evaluation of energy-saving technologies for residential purposes," IEEE PES General Meeting, pp. 1-8, Minneapolis, MN, 2010.

[4] M. Pritoni, J. Lamarche, K. Cheney and O. Sachs, "Home Energy Management: Products \& Trends," In Proceedings of the Summer Study on Energy Efficiency in Building Conference (ACEEE), pp. 165-175, 2012.

[5] Z. Yu, L. Jia, M. C. Murphy-Hoye, A. Pratt and L. Tong, "Modeling and Stochastic Control for Home Energy Management," in IEEE Transactions on Smart Grid, vol. 4, no. 4, pp. 2244-2255, Dec. 2013.

[6] G.Conte and D. Scaradozzi, "Viewing Home Automation Systems as Multiple Agents Systems,"
In Proceedings of the RoboCUP2003, Padova, Italy, 2003.

[7] A. Z. Alkar and U. Buhur, "An Internet based wireless home automation system for multifunctional devices," in IEEE Transactions on Consumer Electronics, vol. 51, no. 4, pp. 1169 1174, Nov. 2005.

[8] N. Jawarkar, V. Ahmed, S. A. Ladhake, and R. D. Thakare, "Microcontroller based Remote Monitoring using Mobile through Spoken Commands," Journal of Networks, pp. 58-6, Vol. 3, No. 2, 2008.

[9] M. G. Golzar and H. Tajozzakerin, "A New Intelligent Remote Control System for Home Automation and Reduce Energy Consumption," In Proceedings of the Fourth Asia International Conference on Mathematical/Analytical Modelling and Computer Simulation, pp. 174-180, Kota Kinabalu, Malaysia, 2010.

[10] M. H. Assaf, R. Mootoo, S. R. Das, E. M. Petriu, V. Groza and S. Biswas, "Sensor based home automation and security system," In Proceedings of the IEEE International Instrumentation and Measurement Technology Conference, pp. 722727, Graz, 2012.

[11] H. C. Jo, S. Kim and S. K. Joo, "Smart heating and air conditioning scheduling method incorporating customer convenience for home energy management system," In Proceedings of the IEEE Transactions on Consumer Electronics, vol. 59, no. 2, pp. 316-322, May 2013

[12] F. Baig, A. Mahmood, N. Javaid, S. Razzaq, N. Khan and Z. Saleem, "Smart Home Energy Management System for Monitoring and Scheduling of Home Appliances Using Zigbee," Journal of Basic and Applied Scientific Research, Vol. 3, No. 5, pp. 880-891, 2013.

[13] B. Mubdir, A. Al-Hindawi and N.Hadi, "Design of Smart Home Energy Management System for Saving Energy," European Scientific Journal. Edition, pp. 521-536, Vol. 12, No. 33, 2016.

[14] Christopher Cox, "Essentials of UMTS", (C) Cambridge University Press, 2008.

[15] Shanghai Sendtrue Technologies Co., "SM5100BD GSM/GPRS Module Hardware Specification", www.sparkfun.com.

[16] Future Technology Devices International Limited, "FT232R USB UART IC Datasheet", Version 2.10, 2010 . 